Review

\title{
New Tricks for an Old (Hedge)Hog: Sonic Hedgehog Regulation of Astrocyte Function
}

\author{
A. Denise R. Garcia (D
}

check for

updates

Citation: Garcia, A.D.R. New Tricks for an Old (Hedge)Hog: Sonic Hedgehog Regulation of Astrocyte Function. Cells 2021, 10, 1353. https://doi.org/10.3390/ cells10061353

Academic Editor: Elisabeth Traiffort

Received: 10 May 2021

Accepted: 27 May 2021

Published: 30 May 2021

Publisher's Note: MDPI stays neutral with regard to jurisdictional claims in published maps and institutional affiliations.

Copyright: (C) 2021 by the author. Licensee MDPI, Basel, Switzerland. This article is an open access article distributed under the terms and conditions of the Creative Commons Attribution (CC BY) license (https:/ / creativecommons.org/licenses/by/ $4.0 /)$.
Department of Biology, Drexel University, Philadelphia, PA 19104, USA; adg82@drexel.edu

\begin{abstract}
The Sonic hedgehog (Shh) molecular signaling pathway is well established as a key regulator of neurodevelopment. It regulates diverse cellular behaviors, and its functions vary with respect to cell type, region, and developmental stage, reflecting the incredible pleiotropy of this molecular signaling pathway. Although it is best understood for its roles in development, Shh signaling persists into adulthood and is emerging as an important regulator of astrocyte function. Astrocytes play central roles in a broad array of nervous system functions, including synapse formation and function as well as coordination and orchestration of CNS inflammatory responses in pathological states. Neurons are the source of Shh in the adult, suggesting that Shh signaling mediates neuron-astrocyte communication, a novel role for this multifaceted pathway. Multiple roles for Shh signaling in astrocytes are increasingly being identified, including regulation of astrocyte identity, modulation of synaptic organization, and limitation of inflammation. This review discusses these novel roles for Shh signaling in regulating diverse astrocyte functions in the healthy brain and in pathology.
\end{abstract}

Keywords: Sonic hedgehog; astrocyte; glia; inflammation; neuron-astrocyte communication

\section{Introduction}

Hedgehog $(\mathrm{Hh})$ signaling has long been recognized as a key molecular signaling pathway orchestrating nervous system development. Initially identified in Drosophila for its role in segmentation and patterning of developing larvae [1], the pathway is evolutionarily conserved, and its vertebrate homolog, Sonic hedgehog (Shh), exerts powerful regulation over various aspects of vertebrate neurodevelopment. Shh signaling establishes the ventral identity of cells in the neural tube of early embryos [2] and is required for specifying ventral neuron and oligodendrocyte cell fate of uncommitted neural progenitors [3-6]. Shh also functions as an axon guidance molecule, directing developing axons towards appropriate target areas [7-10]. In the cerebellum, Shh acts as a mitogen, regulating proliferation of granule cell precursors [11,12]. However, Shh signaling persists into adulthood throughout the brain, where it is transduced in astrocytes $[13,14]$, one of two primary classes of macroglial cells in the central nervous system (CNS). Whereas Shh signaling during development regulates the behaviors of neural precursor and progenitor cells as well as immature neurons, astrocytes are fully differentiated, postmitotic cells, suggesting that its functional role in these cells is likely to differ substantially from that in development. Indeed, emerging evidence shows that Shh signaling plays a role in astrocyte modulation of synaptic function in the healthy brain and also restricts inflammation under pathological conditions. In addition to astrocytes, Shh signaling is also found in adult neural stem cells residing in the subventricular zone (SVZ) and hippocampus, where its activity is required to maintain their self-renewal [15-17]. In this review, we focus on the emerging work uncovering the role of Shh signaling in astrocytes.

Early studies identified multiple components of the Shh signaling pathway throughout several regions of the CNS $[18,19]$. Much of the early focus on Shh signaling in the adult CNS centered on its role in regulating adult neural stem cell (NSC) populations in the 
subventricular zone (SVZ) lining the lateral ventricles and in the hippocampus [15,20,21]. These cells express glial acidic fibrillary protein $(g f a p)[22,23]$ and possess many characteristics shared with astrocytes [22,24]. Perturbations in the Shh signaling pathway impair proliferation and maintenance of these adult NSC populations [17,25-27], consistent with its roles in neurodevelopment. Using genetic tools, Shh activity was later identified in discrete populations of astrocytes throughout the brain $[13,14]$. Indeed, the vast majority of cells transducing Shh signaling in adulthood correspond to mature, differentiated astrocytes. Shh is expressed by neurons $[13,14,28]$, identifying Shh signaling as a molecular pathway mediating neuron-astrocyte communication. Indeed, a growing body of evidence suggests it is involved in complex and multifaceted cell-cell interactions that support modulation of synaptic organization and function in the healthy brain.

Transduction of Shh signaling is initiated by Shh binding to its receptor patched 1 (PTC1), a 12-pass transmembrane receptor. Binding of Shh to PTC1 relieves inhibition of a second transmembrane protein, smoothened (SMO), a member of the $G$ protein-coupled receptor (GPCR) family. Three GLI proteins, GLI1, GLI2, and GLI3, belonging to the family of zinc-finger transcription factors, are the primary transcriptional effectors of Shh signaling in vertebrates and possess both activator and repressor functions. Activation of SMO promotes the transport of full-length, activated GLI2 to the nucleus where it subsequently promotes transcription of Shh target genes, including Gli1. Because Gli1 activation occurs only in the presence of high levels of Shh activity, its transcriptional activation serves as a reliable readout of Shh signaling [29]. In the absence of Shh, GLI2 and GLI3 are truncated by post-translational proteolytic processing that represses transcription. Comprehensive reviews on the molecular mechanics of Shh signaling are available, and the reader is referred to some of these here [30-32].

Astrocytes encompass a complex and functionally diverse population of cells and are now recognized for their essential roles in a broad array of nervous system functions. Astrocytes are required for synapse formation $[33,34]$ and are increasingly implicated in neural circuit organization and function [35-39]. They also regulate homeostatic levels of ions, such as $\mathrm{K}^{+ \text {, }}$ and are responsible for rapid clearance of neurotransmitters such as glutamate from the synapse [40-42]. Together with endothelial cells and pericytes, astrocytes promote blood-brain barrier (BBB) integrity, limiting access of blood-borne molecules and cells to CNS parenchyma [43]. Beyond their roles in the healthy CNS, astrocytes respond to nearly all manner of CNS damage, including acute insults such as stroke or spinal cord injury, as well as chronic neurodegenerative disorders such as Alzheimer's disease [44]. Astrocytes produce and respond to inflammatory cytokines and facilitate the recruitment or restriction of inflammatory cells to sites of injury. Given the breadth of astrocyte contributions to CNS function, much remains to be discovered regarding the underlying molecular mechanisms responsible for orchestrating such diverse functional properties. There is growing evidence that Shh signaling in astrocytes plays an important role in regulating a number of these functions, from synapse organization to restricting inflammation.

\section{Shh Signaling in the Adult Brain}

Early work mapped multiple components of the Shh signaling pathway throughout the adult brain by in situ hybridization $[18,19]$, establishing its persistence in the nervous system beyond neurodevelopment. Transcripts for Shh were found in ventral forebrain structures, such as the hypothalamus and septum, and most prominently in cerebellar Purkinje cells. Shh transcripts were also detected in cells residing in deep layers of the cortex [45]. Transcripts for Ptc and Smo were also found in these regions, as well as regions that lacked Shh transcripts, but were targets of Shh-containing regions, suggesting both local and long-distance signaling [46]. Using genetic tools, later studies identified cells expressing Gli1 in these regions, as well as in adult neural stem cell populations, further confirming transcriptional activity of the Shh pathway throughout the adult forebrain $[14,15,27]$. Colocalization analysis with cell-type-specific markers established neurons as the source 
of Shh ligand, whereas Gli1-expressing were identified as astrocytes, establishing these cells as the predominant cells transducing Shh signaling outside of the adult neurogenic niches [14] (Figure 1). Consistent with this, astrocytes also express Gli2, Gli3, and Ptc [14], demonstrating that these cells possess the necessary machinery to transduce the pathway. Whereas Gli1 expression was found predominantly in astrocytes, whether Gli2, Gli3, and $P t c$ are similarly restricted to astrocytes is not known. Noncanonical, Gli-independent Shh signaling occurs in neurons [28,47], suggesting that Ptc and Smo are likely expressed in these cells. Gli1-expressing astrocytes are most abundant in ventral regions, such as the hypothalamus, amygdala, and septum, but are also found in substantial fractions of astrocytes in the globus pallidus and in the neocortex [14,18]. In contrast, Gli1-expressing astrocytes are notably absent in the striatum and in white matter tracts [14] (Figure 1). This characteristic distribution may reflect functionally distinct populations of cells. Alternatively, this may instead reflect repression of Shh activity in a regionally defined manner. Indeed, other components of the pathway, including Gli2, Gli3, and Ptc exhibit a much broader distribution in the adult brain than Gli1 and are found in regions where Gli1 is noticeably absent, such as in the striatum [14] (Figure 1). Notably, Gli3, a transcriptional repressor of Shh activity, is found in the striatum and in white matter, which are largely devoid of cells expressing Gli1, suggesting that Shh signaling is actively repressed in these regions. Thus, the distribution of multiple components of the pathway suggests that many more cells possess the machinery to transduce Shh signaling than might be expected based on Gli1 expression alone. Shh exerts powerful mitogenic functions, and the activity of the pathway must be tightly regulated since aberrant activation is associated with tumor formation [48]. Disentangling the physiological roles of Shh signaling in astrocyte function from its tumorigenic properties would be interesting for future studies to address.

Although Shh signaling is found in many regions throughout the brain, activity of the pathway varies across regions. The proportion of astrocytes expressing Gli1 differs across regions. In the cortex, $\sim 25-30 \%$ of astrocytes express Gli1 [14,49], whereas the vast majority of astrocytes in the hypothalamus are Gli1-positive [14,50]. This is generally correlated with the abundance of Shh-expressing neurons in some regions. In the hypothalamus and globus pallidus, for example, the number of neurons expressing $S h h$ is relatively high (Figure 1). This heterogeneity in activity of the pathway between regions suggests molecular heterogeneity and differential regulation of astrocytes both between regions and within a given region. Indeed, the functional diversity of astrocytes is of intense interest; however, the molecular identity and regulation of distinct astrocyte populations remain poorly understood [37,51-53]. It is interesting to consider whether Shh signaling confers unique functional properties or genetic signatures in specific populations of astrocytes.

Cells expressing Shh are most abundant in the hypothalamus and medial septum but are also found in the neocortex. In the cerebellum, Purkinje cells produce Shh that is received by neighboring Bergmann glia [13]. The precise mechanism by which Shhexpressing neurons release Shh and communicate to astrocytes is not well understood. There is a close correspondence between Shh and Gli1, with regions showing a high abundance of Shh-expressing cells also showing a high abundance of Gli1-expressing cells, such as in the hypothalamus, suggesting that Shh may be released locally, mediating local communication between neurons and neighboring astrocytes. However, Shh may also be transported axonally, indicating the potential for long-range communication between these cells. Shh transcripts have been detected in retinal ganglion cell axons [9,54,55]. In addition, although astrocytes in the striatum do not express Gli1, conditional deletion of Shh from midbrain dopaminergic neurons leads to a progressive degeneration of midbrain $\mathrm{TH}+$ cells as well as their fast-spiking, cholinergic striatal targets [47], suggesting that noncanonical, Gli-independent Shh activity occurs in these neurons. 
Shh

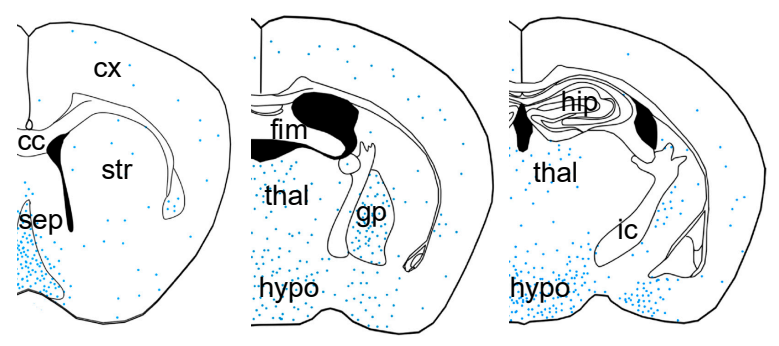

Gli1

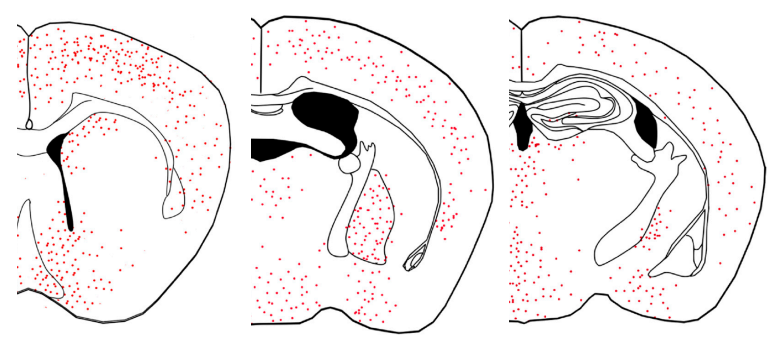

Gli2
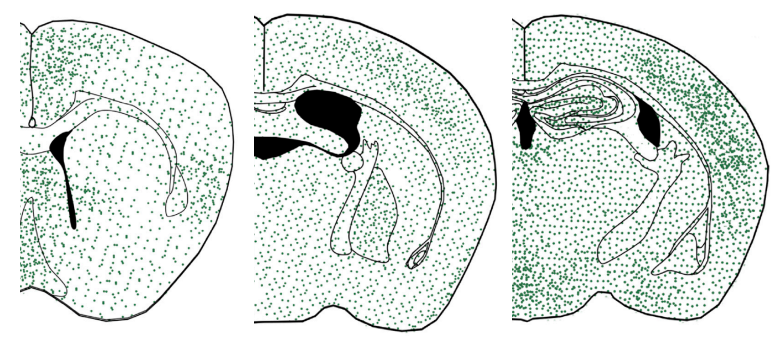

Gli3
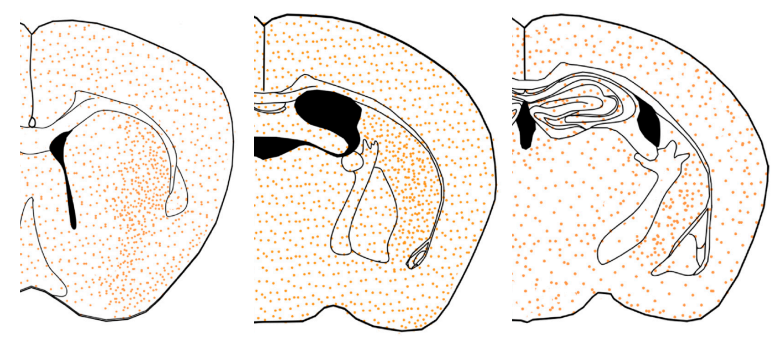

Ptc
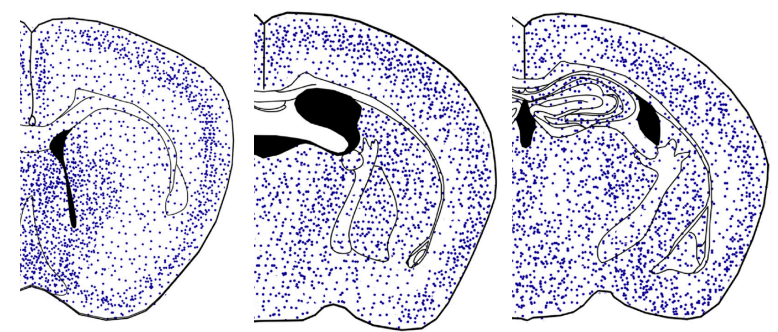

Figure 1. Schematic depicting the relative distribution of various components of the Shh signaling pathway in the intact, adult forebrain across the anterior-posterior axis. Data derived from genetic labeling, as reported by Garcia et al. (2010), and in situ hybridization studies [18,19,45]. Note the relative concordance in distribution of cells expressing Shh and Gli1, whereas cells expressing Gli2, Gli3, and Ptc are found in several regions where Gli1 expression is absent. Shh is expressed by neurons, whereas Gli1, Gli2, Gli3, and Ptc are expressed by astrocytes [14]. cc, corpus callosum; cx, cortex; fim, fimbria; gp, globus pallidus; hip, hippocampus; hypo, hypothalamus; ic, internal capsule; sep, septum; str, striatum; thal, thalamus.

\section{Shh Signaling in Astrocyte Modulation of Synapses}

The last twenty or so years in neuroscience have seen renewed interest in and heightened attention on the role of astrocytes in synaptic function. Despite their former reputation as simple support cells responsible for providing trophic support for neurons, astrocytes are now recognized as a key cellular element of synapses $[33,56]$. Astrocyte processes ensheath synapses $[57,58]$ and are enriched with various channels and transporters that 
promote healthy synaptic function. Clearance of glutamate from the synapse is performed predominantly by astrocytes through the glutamate transporters GLT1 and GLAST1 [59,60], which are found on astrocyte processes. Likewise, astrocytes regulate extracellular $\mathrm{K}^{+}$ homeostasis, through Kir4.1, an inwardly rectifying $\mathrm{K}^{+}$channel [61]. Pioneering work near the turn of the century demonstrated the requirement of astrocytes for synapse formation and function in vitro [34,62]. Significant advances have since been made identifying a number of astrocyte-derived molecules that are required to establish, maintain, and ensure proper function of synapses [33].

Although the gene expression programs regulated by Shh signaling in astrocytes are not yet well understood, studies using cell-type-specific gene deletion strategies to selectively perturb Shh signaling in astrocytes have identified key synapse-associated genes that are Shh-dependent. Most notably, Kir4.1, encoded by the gene KCNJ10, is dysregulated in mice with astrocyte-specific deletions of Smo [13,49]. Kir4.1 facilitates the rapid clearance of $\mathrm{K}^{+}$ions from the synapse, ensuring appropriate extracellular $\left[\mathrm{K}^{+}\right]$necessary for appropriate neuronal firing. Loss of Kir4.1 increases neuronal excitability $[63,64]$. Selective deletion of $S m o$ in astrocytes leads to a reduction in Kir4.1 expression accompanied by heightened excitability of neurons $[13,49]$. In addition, Shh signaling is required for expression of the AMPA receptor subunits GluA1 and GluA4 as well as the glutamate transporter GLAST in Bergmann glial cells of the cerebellum [13]. Ectopic Shh activity in cerebellar velate astrocytes, which normally exhibit low levels of Shh activity, causes them to adopt a transcriptional profile that more closely resembles that of Bergmann glia, including increased expression of GluA1 and GluA4 [13], suggesting that Shh signaling is sufficient to promote expression of genes associated with synapse function.

Astrocyte modulation of synaptic plasticity and organization also requires Shh signaling. In the neocortex, selective deletion of Smo in astrocytes leads to an overabundance of dendritic spines selectively in the apical dendrites of deep-layer neurons [49], coinciding with the enrichment of astrocytes expressing Gli1 in layers 4 and 5. Notably, neurons in the upper layers, where Shh activity is largely absent, show no such perturbation in spine density. Chronic, in vivo imaging by two-photon microscopy shows that spines in Smo conditional knockout (CKO) mice exhibit increased survival, suggesting that synaptic plasticity is impaired following the loss of Shh activity in astrocytes. Interestingly, these spine phenotypes emerge during postnatal development and persist into adulthood. Aberrant circuit formation and synaptic plasticity characterize a number of neurodevelopment disorders, including fragile $\mathrm{X}$ syndrome, Rett syndrome, and autism spectrum disorders (ASDs). The identification of a role for Shh signaling in astrocyte modulation of synaptic organization raises the question of whether targeting Shh activity in astrocytes may provide benefits that mitigate or reverse such aberrant synaptic organization and function.

Astrocyte transduction of Shh signaling is most pronounced in the hypothalamus, in which at least $80 \%$ of astrocytes express Gli1, coinciding with a high abundance of Shh-expressing neurons in this region $[14,50]$. The hypothalamus plays a central role in key homeostatic behaviors, including appetite and energy expenditure. Genetic activation of Shh signaling by astrocyte-specific ablation of Ptc produces lean mice that fail to gain weight with age [50]. Moreover, when challenged with a high-fat diet, these mice fail to show diet-induced weight gain and protection against diet-induced elevated glucose and insulin resistance. Activation of Shh signaling in astrocytes increased expression of insulin receptor selectively in the hypothalamus. These observations demonstrate that Shh signaling regulates energy metabolism and protects against dysregulation of energy metabolism associated with aging and obesity. This is further supported by the observation that $S h h$ transcripts in the hypothalamus are reduced in leptin-deficient mice $\left(L e p^{o b}\right)$ [65].

\section{Astrocyte-Mediated Inflammation and the Role of Shh Signaling}

Beyond their roles as modulators of synapse formation and function in the healthy brain, astrocytes have gained increasing recognition as key cellular effectors of both proand anti-inflammatory functions. Astrocyte end-feet line blood vessels and produce both 
pro- and anti-inflammatory signals that actively recruit or limit leukocyte invasion [66]. Functional interactions between endothelial cells and astrocytes form the BBB, restricting the entry of blood-borne leukocytes into CNS parenchyma [43]. Perturbations of BBB integrity, such as those occurring following injury or in certain neurological disorders such as multiple sclerosis, permit the entry of inflammatory molecules and peripheral immune cells that interfere with CNS function or can exacerbate pathological conditions. Growing evidence shows that Shh signaling limits inflammation and promotes BBB integrity.

Ischemic-induced activation of microglia is reduced in mice treated with cyclopamine, a powerful antagonist of SMO [67]. Conversely, activation of Shh activity following middle cerebral artery occlusion reduces levels of $T N F \alpha, I L-6$, and $I L-1 \beta$ transcripts and increases expression of tight junction proteins $\mathrm{ZO}-1$ and occludin, with a concomitant reduction in permeability of the BBB $[68,69]$. Following a stab wound, peripheral leukocytes invade parenchymal tissues surrounding the lesion. Application of SAG, an agonist of the Shh pathway, reduces macrophage accumulation in the parenchyma [70]. However, this effect is abolished in mice carrying a selective deletion of Smo in astrocytes, suggesting that astrocytes are key cellular effectors of the anti-inflammatory effects of Shh signaling. In support of this, overactivation of Shh signaling specifically in astrocytes, achieved by deleting Ptc, lowers TNF $\alpha$ levels in the cortex [50]. Pharmacological blockade of Shh activity by the SMO antagonist cyclopamine increases the extravasation of plasma proteins into the CNS in vivo [71]. Interestingly, selective deletion of Smo in endothelial cells reduces the expression of tight junction proteins such as occludin, claudin-3, claudin-5, and ZO1, with a concomitant reduction in BBB permeability, demonstrating a role for Shh activity in endothelial cell modulation of BBB integrity. The authors further demonstrate a reduction in astrocyte association with blood vessels, suggesting that endothelial cells produce a cue that attracts astrocyte end-feet and that this cue is Smo-dependent. This suggests that Shh signaling mediates bidirectional communication between astrocyte end-feet and endothelial cells that promotes BBB structure and function. Identifying the Smo-dependent cues in endothelial cells that regulate astrocyte association with blood vessels will shed light on molecular signals that establish and maintain the BBB, which is essential for restricting inflammation. One candidate is Desert hedgehog $(\mathrm{DHH})$, a member of the hedgehog family of signaling molecules. DHH mediates cell-cell communication between endothelial cells and promotes BBB function [72]. Endothelial cell-specific deletion of DHH increases BBB permeability at the endothelial cell barrier while decreasing astrocyte permeability, restricting inflammatory cells that escape the endothelial barrier to the perivascular space. These observations demonstrate that $\mathrm{Hh}$ signaling mediates complex interactions between endothelial cells and astrocytes that promote BBB integrity, while also highlighting the need for further studies to dissect the precise roles of the pathway in different cell types.

Interestingly, several studies have identified astrocytes as the source of Shh in the brain following injury $[67,71,73,74]$. However, genetic labeling studies in $S h h^{C r E R}$ mice identified Shh only in neurons and did not detect transcriptional activation of Shh in any astrocytes $[13,14]$. In support of this, a recent study using single-cell RNA sequencing of cells associated with brain vasculature showed an absence of Shh transcripts in astrocytes [75]. One possibility is that the injured environment stimulates Shh expression in astrocytes. Injury studies using genetic labeling and fate mapping approaches are needed to better understand the cellular source of Shh under pathological conditions. Nevertheless, it is clear that Shh signaling limits inflammation through its actions in astrocytes and endothelial cells. In addition, inflammation itself may also regulate Shh activity. IL-1 $\beta$ reduced Shh mRNA in cultured astrocytes [76]. In vivo, transcriptional activation of Gli1 is reduced in astrocytes as early as 24 hours following injury, but it is restored to baseline levels two weeks later [70], as injury-induced inflammation resolves [77]. These studies identify a role for Shh signaling in astrocyte-mediated regulation of inflammation and suggest this pathway may serve as a potential target for therapeutic interventions against inflammation in injury or disease. Elucidating the molecular cues that regulate the activity 
of the pathway would advance our understanding of the precise mechanism by which Shh signaling exerts its anti-inflammatory benefits in the nervous system.

\section{Shh Signaling in Endogenous Progenitors and Reactive Gliosis after Injury}

The mitogenic properties of Shh signaling in the developing and postnatal CNS are well established. Shh activity promotes proliferation of neural precursors in the embryonic spinal cord and granule cell precursor cells in the cerebellum [12,78,79]. In the adult CNS, proliferation and maintenance of neural stem cells (NSCs) residing in the subventricular zone (SVZ) and hippocampus are similarly Shh-dependent $[20,21,25,27]$. Outside these neurogenic niches, however, most neural cells, including astrocytes, are postmitotic in the healthy and intact CNS. However, injury can stimulate proliferation of both endogenous progenitors residing within the neurogenic niches of the adult brain and local cells at or near the injury site, and growing evidence shows a role for Shh signaling in regulating injury-induced proliferation.

Consistent with its mitogenic properties in the developing CNS, early studies demonstrated that application of Shh or agonists of the pathway increase proliferation of local endogenous progenitor cells following contusion or demyelinating injuries of the spinal cord $[80,81]$. Similar observations have now been reported following various injury models, including ischemia, traumatic brain injury, or kainic acid injection $[67,68,82]$. Conversely, pharmacological agents that block pathway activity reduce proliferation $[67,83,84]$. Cell type analysis of proliferating cells shows that Shh signaling stimulates proliferation of local oligodendrocyte progenitors $[73,85,86]$ and promotes proliferation of adult NSCs in the SVZ and hippocampus [84,87]. Importantly, in studies of demyelinating lesions, there is evidence that Shh signaling in adult NSCs promotes structural and functional neural repair. Fate mapping experiments following a demyelinating lesion in the corpus callosum show that Gli1-expressing NSCs are recruited into the lesion and differentiate into myelinating oligodendrocytes and that Shh activity promotes their proliferation [86,88,89]. Interestingly, SVZ-derived Gli1-expressing NSCs downregulate Gli1 expression upon arrival in the corpus callosum, and genetic ablation of Gli1 improved remyelination, suggesting that transcriptional silencing of Gli1 activity promotes remyelination [88]. Pharmacological stimulation of Gli1 activity with the agonist GANT61 in experimental autoimmune encephalitis (EAE) mice enhanced myelination, improved neuronal survival, and lowered the clinical score of mice during relapse.

In addition to neural stem and progenitor cells, astrocytes can also exhibit injuryinduced proliferation, together with other complex behaviors in response to injury. These behaviors are collectively referred to as reactive astrogliosis and include dramatic changes in morphology, gene expression, production, and response to various molecular cues [44]. Reactive astrocytes exhibit context-dependent behaviors that vary with respect to lesion type, severity, and distance from focal insults. In severe injuries, such as ischemia or spinal cord injury, reactive astrocytes at the injury site proliferate, producing glial scar borders that effectively isolate blood-borne immune cells and restrict their invasion into CNS parenchyma [90]. The well-established effects of Shh signaling on the proliferation of various neural progenitor populations suggest that the proliferation of reactive astrocytes is similarly regulated. In support of this idea, upregulation of Shh activity has been observed in various injury models, including spinal cord injury, ischemia, traumatic brain injury, and demyelination $[67,73,84,91-93]$. Interestingly, noninvasive injuries, such as neurodegeneration, fail to increase Shh expression and do not trigger the proliferation of reactive astrocytes [94]. Reactive astrocytes isolated from the cortex following a stab wound generate neurospheres in vitro [94]. The addition of Shh to the cultures increases the number of neurospheres generated, whereas administration of cyclopamine, a selective antagonist of Shh signaling, to mice abrogates neurosphere formation. These observations demonstrate the requirement for Shh activity in reactive astrocyte proliferation in vitro and further suggest that Shh signaling may confer NSC-like properties on these cells. 
Unexpectedly, however, mice carrying a genetic deletion of Smo selectively in Gfapexpressing cells (Gfap Smo CKO) show no difference in proliferation following a cortical stab wound [70]. Further, genetic labeling of cells expressing Gli1 shows a pronounced reduction in the number of Gli1-expressing cells following injury. Because high levels of Shh activity stimulate transcriptional activation of Gli1, the application of these genetic tools provides a reliable readout of Shh activity in the injured microenvironment. Transgenic reporter mice carrying the lacZ gene targeted to the Gli1 locus (Gli1 ${ }^{l a c Z /+}$ ) show that as early as 24 hours after stab wound, there are fewer Gli1-expressing cells in the cortex [70], demonstrating downregulation of Shh activity after injury. These observations are supported by studies in which Gli1-expressing cells are labeled by tamoxifen administration after injury. Using this approach, fewer Gli1-expressing cells are labeled by tamoxifen after both traumatic brain injury and cuprizone-induced demyelination when compared to tamoxifen administered to control, uninjured mice $[70,87,95]$. These observations argue against a role for Shh signaling in the proliferation of reactive astrocytes following injury and suggest that Shh activity is repressed, at least during the acute phases of injury. This contrasts with the studies discussed above and highlights the need for further studies to understand the nature of the pathway in pathological circumstances.

\section{Outstanding Questions}

Although numerous independent studies now demonstrate a role for Shh signaling after injury, conflicting reports in the literature leave open several questions surrounding the precise nature of Shh activity in the injured or diseased CNS. Most notably, whether Shh signaling is upregulated or downregulated after injury and the cellular source of Shh after injury remain poorly understood. In general, studies reporting an increase in Shh activity and localization of the ligand in astrocytes have relied primarily on antibody staining for Shh $[68,71,73,91]$, whereas studies reporting a reduction of Shh activity and localization of ligand in neurons have relied on genetic tools $[13,70,87]$. Because Shh is secreted, the possibility exists that antibody recognition of Shh on astrocytes may result from recognition of Shh bound to the surface of astrocytes. Notably, antibodies to Shh have been shown to recognize other members of the hedgehog signaling family, Indian hedgehog $(\mathrm{IHH})$ and Desert hedgehog (DHH) [96]. Although Shh is the predominant member of the Hh family in the CNS, expression of Dhh was reported in CNS endothelial cells in vitro and in human and mouse tissues [72]. Alternatively, these conflicting results may reflect discordance between protein and transcript. The development of novel tools, including specific antibodies that reliably and specifically detect Shh and its molecular components, such as PTC, SMO, and the GLI proteins, and that are validated against genetic models, together with the application of genetic models or high-resolution RNA sequencing in various injury models would advance our understanding of Shh signaling in astrocytemediated inflammation. Such work would facilitate the development of novel therapeutic strategies aimed at mitigating the neurological deficits associated with neuroinflammation.

The studies discussed here outline diverse roles for Shh signaling in astrocytes in health and in pathological circumstances. Most injury studies have focused on the inflammatory or proliferative response of astrocytes. However, it will be interesting to examine whether Shh signaling plays a role in astrocyte modulation of synaptic reorganization following injury.

Funding: A.D.R.G. is funded by R01NS096100 and R21NS116664.

Acknowledgments: Special thanks to Marissa Fu for technical assistance in figure preparation and all of the members of the lab for thoughtful discussions.

Conflicts of Interest: The authors declare no conflict of interest. 


\section{References}

1. Nüsslein-Volhard, C.; Wieschaus, E. Mutations affecting segment number and polarity in Drosophila. Nature 1980, 287, 795-801. [CrossRef]

2. Roelink, H.; Augsburger, A.; Heemskerk, J.; Korzh, V.; Norlin, S.; I Altaba, A.R.; Tanabe, Y.; Placzek, M.; Edlund, T.; Jessell, T.; et al. Floor plate and motor neuron induction by vhh-1, a vertebrate homolog of hedgehog expressed by the notochord. Cell 1994, 76, 761-775. [CrossRef]

3. Ericson, J.; Morton, S.; Kawakami, A.; Roelink, H.; Jessell, T.M. Two Critical Periods of Sonic Hedgehog Signaling Required for the Specification of Motor Neuron Identity. Cell 1996, 87, 661-673. [CrossRef]

4. Jessell, T.M. Neuronal specification in the spinal cord: Inductive signals and transcriptional codes. Nat. Rev. Genet. 2000, 1, 20-29. [CrossRef]

5. Orentas, D.; Hayes, J.; Dyer, K.; Miller, R. Sonic hedgehog signaling is required during the appearance of spinal cord oligodendrocyte precursors. Development 1999, 126, 2419-2429. [CrossRef] [PubMed]

6. Rowitch, D.H.; Kriegstein, A.R. Developmental genetics of vertebrate glial-cell specification. Nat. Cell Biol. 2010, 468, 214-222. [CrossRef]

7. Charron, F.; Stein, E.; Jeong, J.; McMahon, A.P.; Tessier-Lavigne, M. The morphogen sonic hedgehog is an axonal chemoat-tractant that collaborates with netrin-1 in midline axon guidance. Cell 2003, 113, 11-23. [CrossRef]

8. Peng, J.; Fabre, P.J.; Dolique, T.; Swikert, S.M.; Kermasson, L.; Shimogori, T.; Charron, F. Sonic Hedgehog Is a Remotely Produced Cue that Controls Axon Guidance Trans-axonally at a Midline Choice Point. Neuron 2018, 97, 326-340.e4. [CrossRef] [PubMed]

9. Trousse, F.; Martí, E.; Gruss, P.; Torres, M.; Bovolenta, P. Control of retinal ganglion cell axon growth: A new role for Sonic hedgehog. Development 2001, 128, 3927-3936. [CrossRef] [PubMed]

10. Wu, Z.; Makihara, S.; Yam, P.T.; Teo, S.; Renier, N.; Balekoglu, N.; Moreno-Bravo, J.A.; Olsen, O.; Chédotal, A.; Charron, F.; et al. Long-Range Guidance of Spinal Commissural Axons by Netrin1 and Sonic Hedgehog from Midline Floor Plate Cells. Neuron 2019, 101, 635-647. [CrossRef]

11. Dahmane, N.; Ruiz-I-Altaba, A. Sonic hedgehog regulates the growth and patterning of the cerebellum. Development 1999, 126, 3089-3100. [CrossRef]

12. Wechsler-Reya, R.J.; Scott, M.P. Control of Neuronal Precursor Proliferation in the Cerebellum by Sonic Hedgehog. Neuron 1999, 22, 103-114. [CrossRef]

13. Farmer, W.T.; Abrahamsson, T.; Chierzi, S.; Lui, C.; Zaelzer, C.; Jones, E.V.; Bally, B.P.; Chen, G.G.; Théroux, J.-F.; Peng, J.; et al. Neurons diversify astrocytes in the adult brain through sonic hedgehog signaling. Science 2016, 351, 849-854. [CrossRef] [PubMed]

14. Garcia, A.D.R.; Petrova, R.; Eng, L.; Joyner, A.L. Sonic Hedgehog Regulates Discrete Populations of Astrocytes in the Adult Mouse Forebrain. J. Neurosci. 2010, 30, 13597-13608. [CrossRef]

15. Ahn, S.; Joyner, A.L. In vivo analysis of quiescent adult neural stem cells responding to Sonic hedgehog. Nat. Cell Biol. 2005, 437, 894-897. [CrossRef] [PubMed]

16. Álvarez-Buylla, A.; Ihrie, R.A. Sonic hedgehog signaling in the postnatal brain. Semin. Cell Dev. Biol. 2014, 33, 105-111. [CrossRef]

17. Han, Y.-G.; Spassky, N.; Romaguera-Ros, M.; Garcia-Verdugo, J.-M.; Aguilar, A.; Schneider-Maunoury, S.; Alvarez-Buylla, A. Hedgehog signaling and primary cilia are required for the formation of adult neural stem cells. Nat. Neurosci. 2008, 11, $277-284$. [CrossRef]

18. Traiffort, E.; Charytoniuk, D.; Watroba, L.; Faure, H.; Sales, N.; Ruat, M. Discrete localizations of hedgehog signalling com-ponents in the developing and adult rat nervous system. Eur. J. Neurosci. 1999, 11, 3199-3214. [CrossRef]

19. Traiffort, E.; Charytoniuk, D.A.; Faure, H.; Ruat, M. Regional Distribution of Sonic Hedgehog, Patched, and Smoothened mRNA in the Adult Rat Brain. J. Neurochem. 2002, 70, 1327-1330. [CrossRef] [PubMed]

20. Balordi, F.; Fishell, G. Mosaic Removal of Hedgehog Signaling in the Adult SVZ Reveals That the Residual Wild-Type Stem Cells Have a Limited Capacity for Self-Renewal. J. Neurosci. 2007, 27, 14248-14259. [CrossRef]

21. Balordi, F.; Fishell, G. Hedgehog Signaling in the Subventricular Zone Is Required for Both the Maintenance of Stem Cells and the Migration of Newborn Neurons. J. Neurosci. 2007, 27, 5936-5947. [CrossRef]

22. Doetsch, F.; Caillé, I.; Lim, D.A.; García-Verdugo, J.M.; Alvarez-Buylla, A. Subventricular Zone Astrocytes Are Neural Stem Cells in the Adult Mammalian Brain. Cell 1999, 97, 703-716. [CrossRef]

23. Garcia, A.D.R.; Doan, N.B.; Imura, T.; Bush, T.G.; Sofroniew, M.V. GFAP-expressing progenitors are the principal source of constitutive neurogenesis in adult mouse forebrain. Nat. Neurosci. 2004, 7, 1233-1241. [CrossRef] [PubMed]

24. Kriegstein, A.; Alvarez-Buylla, A. The Glial Nature of Embryonic and Adult Neural Stem Cells. Annu. Rev. Neurosci. 2009, 32, 149-184. [CrossRef] [PubMed]

25. Ihrie, R.; Shah, J.; Harwell, C.C.; Levine, J.H.; Guinto, C.D.; Lezameta, M.; Kriegstein, A.R.; Alvarez-Buylla, A. Persistent Sonic Hedgehog Signaling in Adult Brain Determines Neural Stem Cell Positional Identity. Neuron 2011, 71, 250-262. [CrossRef] [PubMed]

26. Lai, K.; Kaspar, B.K.; Gage, F.H.; Schaffer, D.V. Sonic hedgehog regulates adult neural progenitor proliferation in vitro and in vivo. Nat. Neurosci. 2002, 6, 21-27. [CrossRef]

27. Petrova, R.; Garcia, A.D.R.; Joyner, A.L. Titration of GLI3 Repressor Activity by Sonic Hedgehog Signaling Is Critical for Maintaining Multiple Adult Neural Stem Cell and Astrocyte Functions. J. Neurosci. 2013, 33, 17490-17505. [CrossRef] 
28. Harwell, C.C.; Parker, P.R.; Gee, S.M.; Okada, A.; McConnell, S.K.; Kreitzer, A.C.; Kriegstein, A.R. Sonic Hedgehog Expression in Corticofugal Projection Neurons Directs Cortical Microcircuit Formation. Neuron 2012, 73, 1116-1126. [CrossRef]

29. Bai, C.; Stephen, D.; Joyner, A.L. All Mouse Ventral Spinal Cord Patterning by Hedgehog Is Gli Dependent and Involves an Activator Function of Gli3. Dev. Cell 2004, 6, 103-115. [CrossRef]

30. Briscoe, J.; Thérond, P.P. The mechanisms of Hedgehog signalling and its roles in development and disease. Nat. Rev. Mol. Cell Biol. 2013, 14, 416-429. [CrossRef]

31. Fuccillo, M.; Joyner, A.L.; Fishell, G. Morphogen to mitogen: The multiple roles of hedgehog signalling in vertebrate neural development. Nat. Rev. Neurosci. 2006, 7, 772-783. [CrossRef]

32. Ramsbottom, S.A.; Pownall, M.E. Regulation of Hedgehog Signalling Inside and Outside the Cell. J. Dev. Biol. 2016, 4, 23. [CrossRef] [PubMed]

33. Allen, N.J.; Eroglu, C. Cell Biology of Astrocyte-Synapse Interactions. Neuron 2017, 96, 697-708. [CrossRef]

34. Ullian, E.M.; Sapperstein, S.K.; Christopherson, K.S.; Barres, B.A. Control of Synapse Number by Glia. Science 2001, $291,657-661$. [CrossRef] [PubMed]

35. Ackerman, S.D.; Perez-Catalan, N.A.; Freeman, M.R.; Doe, C.Q. Astrocytes close a motor circuit critical period. Nat. Cell Biol. 2021, 592, 414-420. [CrossRef]

36. Huang, A.Y.-S.; Woo, J.; Sardar, D.; Lozzi, B.; Huerta, N.A.B.; Lin, C.-C.J.; Felice, D.; Jain, A.; Paulucci-Holthauzen, A.; Deneen, B. Region-Specific Transcriptional Control of Astrocyte Function Oversees Local Circuit Activities. Neuron 2020, 106, 992-1008.e9. [CrossRef]

37. Khakh, B.S.; Sofroniew, M.V. Diversity of astrocyte functions and phenotypes in neural circuits. Nat. Neurosci. 2015, 18, 942-952. [CrossRef]

38. Kol, A.; Adamsky, A.; Groysman, M.; Kreisel, T.; London, M.; Goshen, I. Astrocytes contribute to remote memory formation by modulating hippocampal-cortical communication during learning. Nat. Neurosci. 2020, 23, 1229-1239. [CrossRef]

39. Mu, Y.; Bennett, D.V.; Rubinov, M.; Narayan, S.; Yang, C.-T.; Tanimoto, M.; Mensh, B.D.; Looger, L.L.; Ahrens, M.B. Glia Accumulate Evidence that Actions Are Futile and Suppress Unsuccessful Behavior. Cell 2019, 178, 27-43. [CrossRef] [PubMed]

40. Anderson, C.M.; Swanson, R.A. Astrocyte glutamate transport: Review of properties, regulation, and physiological functions. Glia 2000, 32, 1-14. [CrossRef]

41. Kuffler, S.W. The Ferrier Lecture-Neuroglial cells: Physiological properties and a potassium mediated effect of neuronal activity on the glial membrane potential. Proc. R. Soc. Lond. Ser.B Biol. Sci. 1967, 168, 1-21. [CrossRef]

42. Sibille, J.; Pannasch, U.; Rouach, N. Astroglial potassium clearance contributes to short-term plasticity of synaptically evoked currents at the tripartite synapse. J. Physiol. 2014, 592, 87-102. [CrossRef]

43. Abbott, N.J.; Rönnbäck, L.; Hansson, E. Astrocyte-endothelial interactions at the blood-brain barrier. Nat. Rev. Neurosci. 2006, 7, 41-53. [CrossRef]

44. Sofroniew, M.V. Astrogliosis. Cold Spring Harb. Perspect. Biol. 2015, 7, a020420. [CrossRef]

45. Charytoniuk, D.; Porcel, B.; Rodríguez-Gómez, J.A.; Faure, H.; Ruat, M.; Traiffort, E. Sonic hedgehog signalling in the developing and adult brain. J. Physiol. 2002, 96, 9-16. [CrossRef]

46. Traiffort, E.; Angot, E.; Ruat, M. Sonic Hedgehog signaling in the mammalian brain. J. Neurochem. 2010, 113, 576-590. [CrossRef] [PubMed]

47. Gonzalez-Reyes, L.E.; Verbitsky, M.; Blesa, J.; Jackson-Lewis, V.; Paredes, D.; Tillack, K.; Phani, S.; Kramer, E.; Przedborski, S.; Kottmann, A.H. Sonic Hedgehog Maintains Cellular and Neurochemical Homeostasis in the Adult Nigrostriatal Circuit. Neuron 2012, 75, 306-319. [CrossRef]

48. I Altaba, A.R.; Sánchez, P.; Dahmane, N. Gli and hedgehog in cancer: Tumours, embryos and stem cells. Nat. Rev. Cancer 2002, 2, 361-372. [CrossRef]

49. A Hill, S.; Blaeser, A.S.; A Coley, A.; Xie, Y.; A Shepard, K.; Harwell, C.C.; Gao, W.-J.; Garcia, A.D.R. Sonic hedgehog signaling in astrocytes mediates cell type-specific synaptic organization. eLife 2019, 8, e45545. [CrossRef]

50. Tirou, L.; Russo, M.; Faure, H.; Pellegrino, G.; Demongin, C.; Daynac, M.; Sharif, A.; Amosse, J.; Le Lay, S.; Denis, R.; et al. Sonic Hedgehog receptor Patched deficiency in astrocytes enhances glucose metabolism in mice. Mol. Metab. 2021, 47, 101172. [CrossRef]

51. Bayraktar, O.A.; Bartels, T.; Holmqvist, S.; Kleshchevnikov, V.; Martirosyan, A.; Polioudakis, D.; Ben Haim, L.; Young, A.M.H.; Batiuk, M.Y.; Prakash, K.; et al. Astrocyte layers in the mammalian cerebral cortex revealed by a single-cell in situ transcriptomic map. Nat. Neurosci. 2020, 23, 500-509. [CrossRef]

52. Batiuk, M.Y.; Martirosyan, A.; Wahis, J.; De Vin, F.; Marneffe, C.; Kusserow, C.; Koeppen, J.; Viana, J.F.; Oliveira, J.F.; Voet, T.; et al. Identification of region-specific astrocyte subtypes at single cell resolution. Nat. Commun. 2020, 11, 1-15. [CrossRef]

53. Lin, C.-C.J.; Yu, K.; Hatcher, A.; Huang, T.-W.; Lee, H.K.; Carlson, J.; Weston, M.C.; Chen, F.; Zhang, Y.; Zhu, W.; et al. Identification of diverse astrocyte populations and their malignant analogs. Nat. Neurosci. 2017, 20, 396-405. [CrossRef]

54. Traiffort, E.; Moya, K.L.; Faure, H.; Hässig, R.; Ruat, M. High expression and anterograde axonal transport of aminoterminal sonic hedgehog in the adult hamster brain. Eur. J. Neurosci. 2001, 14, 839-850. [CrossRef] [PubMed]

55. Wallace, V.; Raff, M. A role for Sonic hedgehog in axon-to-astrocyte signalling in the rodent optic nerve. Development 1999, 126, 2901-2909. [CrossRef] [PubMed] 
56. Araque, A.; Parpura, V.; Sanzgiri, R.P.; Haydon, P.G. Tripartite synapses: Glia, the unacknowledged partner. Trends Neurosci. 1999, 22, 208-215. [CrossRef]

57. Genoud, C.; Quairiaux, C.; Steiner, P.; Hirling, H.; Welker, E.; Knott, G.W. Plasticity of Astrocytic Coverage and Glutamate Transporter Expression in Adult Mouse Cortex. PLoS Biol. 2006, 4, e343. [CrossRef]

58. Ventura, R.; Harris, K.M. Three-Dimensional Relationships between Hippocampal Synapses and Astrocytes. J. Neurosci. 1999, 19, 6897-6906. [CrossRef]

59. Rothstein, J.D.; Martin, L.; Levey, A.I.; Dykes-Hoberg, M.; Jin, L.; Wu, D.; Nash, N.; Kuncl, R.W. Localization of neuronal and glial glutamate transporters. Neuron 1994, 13, 713-725. [CrossRef]

60. Tanaka, K.; Watase, K.; Manabe, T.; Yamada, K.; Watanabe, M.; Takahashi, K.; Iwama, H.; Nishikawa, T.; Ichihara, N.; Kikuchi, T.; et al. Epilepsy and Exacerbation of Brain Injury in Mice Lacking the Glutamate Transporter GLT-1. Science 1997, 276, 1699-1702. [CrossRef]

61. Olsen, M.L.; Sontheimer, H. Functional implications for Kir4.1 channels in glial biology: From $\mathrm{K}^{+}$buffering to cell differentiation. J. Neurochemistry 2008, 107, 589-601. [CrossRef]

62. Pfrieger, F.W. Synaptic Efficacy Enhanced by Glial Cells in Vitro. Sci. 1997, 277, 1684-1687. [CrossRef]

63. Chever, O.; Djukic, B.; McCarthy, K.D.; Amzica, F. Implication of Kir4.1 Channel in Excess Potassium Clearance: An In Vivo Study on Anesthetized Glial-Conditional Kir4.1 Knock-Out Mice. J. Neurosci. 2010, 30, 15769-15777. [CrossRef]

64. Djukic, B.; Casper, K.B.; Philpot, B.D.; Chin, L.-S.; McCarthy, K.D. Conditional Knock-Out of Kir4.1 Leads to Glial Membrane Depolarization, Inhibition of Potassium and Glutamate Uptake, and Enhanced Short-Term Synaptic Potentiation. J. Neurosci. 2007, 27, 11354-11365. [CrossRef]

65. Han, X.; Burger, L.L.; Garcia-Galiano, D.; Sim, S.; Allen, S.J.; Olson, D.P.; Myers, M.G.; Elias, C.F. Hypothalamic and Cell-Specific Transcriptomes Unravel a Dynamic Neuropil Remodeling in Leptin-Induced and Typical Pubertal Transition in Female Mice. iScience 2020, 23, 101563. [CrossRef] [PubMed]

66. Sofroniew, M.V. Astrocyte barriers to neurotoxic inflammation. Nat. Rev. Neurosci. 2015, 16, 249-263. [CrossRef] [PubMed]

67. Pitter, K.; Tamagno, I.; Feng, X.; Ghosal, K.; Amankulor, N.; Holland, E.C.; Hambardzumyan, D. The SHH/Gli pathway is reactivated in reactive glia and drives proliferation in response to neurodegeneration-induced lesions. Glia 2014, 62, 1595-1607. [CrossRef]

68. Chechneva, O.; Mayrhofer, F.; Daugherty, D.J.; Krishnamurty, R.G.; Bannerman, P.; Pleasure, D.; Deng, W. A Smoothened receptor agonist is neuroprotective and promotes regeneration after ischemic brain injury. Cell Death Dis. 2014, 5, e1481. [CrossRef]

69. Xia, Y.-P.; He, Q.-W.; Li, Y.-N.; Chen, S.-C.; Huang, M.; Wang, Y.; Gao, Y.; Huang, Y.; Wang, M.-D.; Mao, L.; et al. Recombinant Human Sonic Hedgehog Protein Regulates the Expression of ZO-1 and Occludin by Activating Angiopoietin-1 in Stroke Damage. PLoS ONE 2013, 8, e68891. [CrossRef]

70. Allahyari, R.V.; Clark, L.; Shepard, K.A.; Garcia, A.D.R. Sonic hedgehog signaling is negatively regulated in reactive astrocytes after forebrain stab injury. Sci. Rep. 2019, 9, 1-14. [CrossRef]

71. Alvarez, J.I.; Dodelet-Devillers, A.; Kebir, H.; Ifergan, I.; Fabre, P.; Terouz, S.; Sabbagh, M.; Wosik, K.; Bourbonnière, L.; Bernard, M.; et al. The Hedgehog Pathway Promotes Blood-Brain Barrier Integrity and CNS Immune Quiescence. Science 2011, 334, 1727-1731. [CrossRef]

72. Mora, P.; Hollier, P.-L.; Guimbal, S.; Abelanet, A.; Diop, A.; Cornuault, L.; Couffinhal, T.; Horng, S.; Gadeau, A.-P.; Renault, M.-A.; et al. Blood-brain barrier genetic disruption leads to protective barrier formation at the Glia Limitans. PLoS Biol. 2020, 18, e3000946. [CrossRef]

73. Amankulor, N.M.; Hambardzumyan, D.; Pyonteck, S.M.; Becher, O.J.; Joyce, J.A.; Holland, E.C. Sonic Hedgehog Pathway Activation Is Induced by Acute Brain Injury and Regulated by Injury-Related Inflammation. J. Neurosci. 2009, 29, 10299-10308. [CrossRef]

74. Michinaga, S.; Inoue, A.; Sonoda, K.; Mizuguchi, H.; Koyama, Y. Down-regulation of astrocytic sonic hedgehog by activation of endothelin ETB receptors: Involvement in traumatic brain injury-induced disruption of blood brain barrier in a mouse model. Neurochem. Int. 2021, 146, 105042. [CrossRef] [PubMed]

75. Vanlandewijck, M.; He, L.; Mäe, M.A.; Andrae, J.; Ando, K.; Del Gaudio, F.; Nahar, K.; Lebouvier, T.; Laviña, B.; Gouveia, L.; et al. A molecular atlas of cell types and zonation in the brain vasculature. Nat. Cell Biol. 2018, 554, 475-480. [CrossRef]

76. Wang, Y.; Jin, S.; Sonobe, Y.; Cheng, Y.; Horiuchi, H.; Parajuli, B.; Kawanokuchi, J.; Mizuno, T.; Takeuchi, H.; Suzumura, A. Interleukin-1 $\beta$ Induces Blood-Brain Barrier Disruption by Downregulating Sonic Hedgehog in Astrocytes. PLoS ONE 2014, 9 , e110024. [CrossRef] [PubMed]

77. Burda, J.E.; Sofroniew, M.V. Reactive Gliosis and the Multicellular Response to CNS Damage and Disease. Neuron 2014, 81, 229-248. [CrossRef]

78. Palma, V.; Lim, D.A.; Dahmane, N.; Sánchez, P.; Brionne, T.C.; Herzberg, C.D.; Gitton, Y.; Carleton, A.; Álvarez-Buylla, A.; i Altaba, A.R. Sonic hedgehog controls stem cell behavior in the postnatal and adult brain. Development 2005, 132, 335-344. [CrossRef]

79. Rowitch, D.; St.-Jacques, B.; Lee, S.M.K.; Flax, J.D.; Snyder, E.Y.; McMahon, A.P. Sonic hedgehogRegulates Proliferation and Inhibits Differentiation of CNS Precursor Cells. J. Neurosci. 1999, 19, 8954-8965. [CrossRef] [PubMed]

80. Bambakidis, N.C.; Miller, R.H. Transplantation of oligodendrocyte precursors and sonic hedgehog results in improved function and white matter sparing in the spinal cords of adult rats after contusion. Spine J. 2004, 4, 16-26. [CrossRef] 
81. Bambakidis, N.C.; Wang, R.-Z.; Franic, L.; Miller, R.H. Sonic hedgehog-induced neural precursor proliferation after adult rodent spinal cord injury. J. Neurosurg. 2003, 99, 70-75. [CrossRef]

82. Pringle, A.K.; Solomon, E.; Coles, B.J.; Desousa, B.R.; Shtaya, A.; Gajavelli, S.; Dabab, N.; Zaben, M.J.; Bulters, D.O.; Bullock, M.R.; et al. Sonic Hedgehog Signaling Promotes Peri-Lesion Cell Proliferation and Functional Improvement after Cortical Contusion Injury. Neurotrauma Rep. 2021, 2, 27-38. [CrossRef] [PubMed]

83. Ferent, J.; Zimmer, C.; Durbec, P.; Ruat, M.; Traiffort, E. Sonic Hedgehog Signaling Is a Positive Oligodendrocyte Regulator during Demyelination. J. Neurosci. 2013, 33, 1759-1772. [CrossRef]

84. Sims, J.R.; Lee, S.-W.; Topalkara, K.; Qiu, J.; Xu, J.; Zhou, Z.; Moskowitz, M.A. Sonic Hedgehog Regulates Ischemia/HypoxiaInduced Neural Progenitor Proliferation. Stroke 2009, 40, 3618-3626. [CrossRef]

85. Bambakidis, N.C.; Wang, X.; Lukas, R.J.; Spetzler, R.F.; Sonntag, V.K.; Preul, M.C. Intravenous Hedgehog Agonist Induces Proliferation of Neural and Oligodendrocyte Precursors in Rodent Spinal Cord Injury. Neurosurgery 2010, 67, 1709-1715. [CrossRef] [PubMed]

86. Sanchez, M.A.; Armstrong, R.C. Postnatal Sonic hedgehog (Shh) responsive cells give rise to oligodendrocyte lineage cells during myelination and in adulthood contribute to remyelination. Exp. Neurol. 2018, 299, 122-136. [CrossRef] [PubMed]

87. Mierzwa, A.J.; Sullivan, G.M.; Beer, L.A.; Ahn, S.; Armstrong, R.C. Comparison of Cortical and White Matter Traumatic Brain Injury Models Reveals Differential Effects in the Subventricular Zone and Divergent Sonic Hedgehog Signaling Pathways in Neuroblasts and Oligodendrocyte Progenitors. ASN Neuro 2014, 6. [CrossRef]

88. Samanta, J.; Grund, E.M.; Silva, H.M.; Lafaille, J.J.; Fishell, G.; Salzer, J.L. Inhibition of Gli1 mobilizes endogenous neural stem cells for remyelination. Nat. Cell Biol. 2015, 526, 448-452. [CrossRef]

89. Sanchez, M.A.; Sullivan, G.M.; Armstrong, R.C. Genetic detection of Sonic hedgehog (Shh) expression and cellular response in the progression of acute through chronic demyelination and remyelination. Neurobiol. Dis. 2018, 115, 145-156. [CrossRef]

90. Wanner, I.B.; Anderson, M.A.; Song, B.; Levine, J.; Fernandez, A.; Gray-Thompson, Z.; Ao, Y.; Sofroniew, M.V. Glial Scar Borders Are Formed by Newly Proliferated, Elongated Astrocytes That Interact to Corral Inflammatory and Fibrotic Cells via STAT3-Dependent Mechanisms after Spinal Cord Injury. J. Neurosci. 2013, 33, 12870-12886. [CrossRef]

91. Jin, Y.; Raviv, N.; Barnett, A.; Bambakidis, N.C.; Filichia, E.; Luo, Y. The Shh Signaling Pathway Is Upregulated in Multiple Cell Types in Cortical Ischemia and Influences the Outcome of Stroke in an Animal Model. PLoS ONE 2015, 10, e0124657. [CrossRef]

92. Seifert, T.; Bauer, J.; Weissert, R.; Fazekas, F.; Storch, M.K. Differential Expression of Sonic Hedgehog Immunoreactivity During Lesion Evolution in Autoimmune Encephalomyelitis. J. Neuropathol. Exp. Neurol. 2005, 64, 404-411. [CrossRef]

93. Wang, Y.; Imitola, J.; Rasmussen, S.; O'Connor, K.C.; Khoury, S.J. Paradoxical dysregulation of the neural stem cell pathway sonic hedgehog-gli1 in autoimmune encephalomyelitis and multiple sclerosis. Ann. Neurol. 2008, 64, 417-427. [CrossRef]

94. Sirko, S.; Behrendt, G.; Johansson, P.; Tripathi, P.; Costa, M.; Bek, S.; Heinrich, C.; Tiedt, S.; Colak, D.; Dichgans, M.; et al. Reactive Glia in the Injured Brain Acquire Stem Cell Properties in Response to Sonic Hedgehog. Cell Stem Cell 2013, 12, 426-439. [CrossRef] [PubMed]

95. Hibbits, N.; Yoshino, J.; Le, T.Q.; Armstrong, R.C. Astrogliosis During Acute and Chronic Cuprizone Demyelination and Implications for Remyelination. ASN Neuro 2012, 4, AN20120062. [CrossRef] [PubMed]

96. Chapouly, C.; Guimbal, S.; Hollier, P.-L.; Renault, M.-A. Role of Hedgehog Signaling in Vasculature Development, Differentiation, and Maintenance. Int. J. Mol. Sci. 2019, 20, 3076. [CrossRef] [PubMed] 